\title{
Epidemiology and Challenges of Neurotraumas Care in the Emergency Department of a Semi-Urban Hospital in Guinea, West Africa
}

\author{
I. S. Souaré1, K. Kaba1, A. B. Bah² ${ }^{*}$, I. Berete², B. D. Tama1, I. S. Souaré2 ${ }^{2}$ L. K. Beavogui2 \\ ${ }^{1}$ Department of Neurosurgery, Hopital de l'amitie Sino-Guineenne, Conakry, Guinea \\ ${ }^{2}$ Department of Neurosurgery, Hopital national Donka, Conakry, Guinea \\ Email: *cushing.bah@gmail.com
}

How to cite this paper: Souaré, I.S., Kaba, K., Bah, A.B., Berete, I., Tama, B.D., Souaré, I.S. and Beavogui, L.K. (2021) Epidemiology and Challenges of Neurotraumas Care in the Emergency Department of a Semi-Urban Hospital in Guinea, West Africa. Open Journal of Modern Neurosurgery, 11, 129-136. https://doi.org/10.4236/ojmn.2021.113016

Received: March 9, 2021

Accepted: May 15, 2021

Published: May 18, 2021

Copyright $\odot 2021$ by author(s) and Scientific Research Publishing Inc. This work is licensed under the Creative Commons Attribution International License (CC BY 4.0).

http://creativecommons.org/licenses/by/4.0/ (c) (i) Open Access

\begin{abstract}
Trauma is one of the most common surgical emergencies admitted in the acute care departments of hospitals in Guinea, West Africa. We carried a study to assess the epidemiological pattern and clinical care of neurotrauma in the emergency department of the Kindia regional hospital, a rural secondary hospital catering to the needs of western Guinea and nearby districts. Data were prospectively collected from December 2019 to March 2020 after receiving the required hospital authorization and informed consent from the patients or relatives. We recorded two hundred cases of neurotraumas (64.5\% of traumatic brain injury cases and $14.5 \%$ of spinal cord injury). Neurotraumas represented $17.7 \%$ of all admitted patients in the department in the study period. The mean age was $25.34 \pm 16.73$, and the age range 16 to 30 was the most affected. The predominance was male, with a sex ratio of 3.43. Motor Vehicle Accident was the leading cause $68.5 \%$, and $73.2 \%$ of them involved a motorcycle. Motorcycle-to-motorcycle collision was responsible for more than a third of neurotraumas. We classified the majority of the cases as mild and low risk neurotrauma representing $62.08 \%$. All patients benefited from medical treatment, and $30.7 \%$ of patients received surgical treatment for associated abdominal, orthopedic, and minor procedures for scalp dilacerations. No patient was referred to a Neurosurgery department, and all living patients were discharged home during the study period with minimal disability. The mortality was $16.3 \%$. Our results could be biased by the lack of interhospital networking and the fact that severe traumatic brain-injured patient dies before seeking medical attention.
\end{abstract}

\section{Keywords}

Neurotrauma, Guinea, Rural, Motor Vehicle Accident, Emergency Department 


\section{Introduction}

Neurotrauma is a general term used to describe any brain injury, the spinal cord, and its covering due to an externally applied mechanical force [1]. It represents a significant public health concern in Guinea, as it could be associated with lifelong complications affecting locomotion, memory, language, and many other higher brain functions [2]. The initial resuscitation in the emergency department of any hospital is critical in assessing the quality of care and a significant determinant of the prognosis. A 2007 literature review reported 10.4 to 83 cases per million per year [3]. Traumas represent the leading cause of death and long-term functional disability in the world [4] [5].

While declining in developed countries, the burden of neurotrauma remains high in the third world due to rapid urbanization and motorization. Motorcycles are more vulnerable in these areas [3].

In Guinea, most epidemiological and quality of care studies have been performed in tertiary hospitals of the capital [2] [6]. There is only one study in a semi-urban setting dating from 2006 in Boke where Beavogui et al. found that 75.11\% of hospital admissions were related to neurotrauma [7].

This study aimed to define the demographics and challenges in the medical care of neurotraumas in another rural health institution in Kindia as part of a multi-institutional data pool for a future metanalysis to generate the national database.

\section{Material and Methods}

A 3-month prospective observational study was carried from December 2019 to March 2020 in the Emergency department of the Regional Hospital of Kindia, a tertiary health institution in the western province of Guinea.

Kindia is the 4th most populated city in Guinea and a significant province of the country. It is $160 \mathrm{~km}$ from the national capital Conakry and a major crossroad for the traffic between the national capital and the Inland. There is no intensive or critical care unit and no CT scan in the complex. The study involved all patients admitted for neurotrauma in the Emergency Department ED in the study period. A proforma was prepared, and the demographic data of all the patients, such as age, sex, marital status, occupation, were recorded. Other data collected included, mechanism of injury, diagnosis, the vitals and GSC, the investigation made, the treatment offered, clinical course, and immediate outcome. Patients were grouped according to the clinical severity as mild for a GSC 13 - 15 (Group 1), Moderate for a GSC 9 - 12 (Group 2), and Severe for a GCS 3 - 8 (Group 3). Patients or families who refused to participate in the study were excluded. Data analysis was done using SPSS statistical program version 21.0, generating simple frequencies for non-numeric variables and simple averages for numeric variables.

\section{Results}

During our study period, we received a total of 1126 patients in the Emergency 
Department of the Kindia regional hospital, of which 200 were analyzed as neurotrauma, i.e., a frequency of $17.76 \%$. The demographics are summarized in $\mathrm{Ta}$ ble 1. Sixty-four-point five percent were injured on the brain and $14.5 \%$ on the spine, whereas $21 \%$ had both injuries. The mean age was $25.34 \pm 16.73$, and the age range 16 to 30 was the most affected. One hundred fifty-four were male, with 46 females giving a sex ratio of 3.43 (Table 2). The mean time from injury to hospital admission after injury was $20.8 \pm 32.3$ hours with $30 \mathrm{~min}$ and 1 -month extremes.

Motor Vehicle Accident (MVA) was the leading cause $68.5 \%$, and $73.2 \%$ of them involved a motorcycle. Most isolated spinal cord injuries were caused by falls. Motorcycle-to-motorcycle collision was responsible for more than a third of neurotraumas, i.e., $33.3 \%$, followed by motorcycle-to-car collision with $17.4 \%$, car and motorcycle skidding against the third party in $16.7 \%$. $45.7 \%$ of MVA

Table 1. Sociodemographic data of the cohort.

\begin{tabular}{ccccc}
\hline \multirow{2}{*}{ Variables } & & \multicolumn{3}{c}{ Neurotrauma } \\
\cline { 2 - 4 } Sex & Male & TBI (\%) & SI (\%) & Both (\%) \\
\hline \multirow{3}{*}{ Age Interval } & Female & $27(58.7)$ & $10(21.7)$ & $9(19.6)$ \\
\cline { 2 - 4 } & $<15$ & $30(81.1)$ & $3(8.1)$ & $4(10.8)$ \\
& $16-30$ & $63(61.2)$ & $15(14.6)$ & $25(24.3)$ \\
& $31-45$ & $17(53.1)$ & $7(21.9)$ & $8(25)$ \\
& $46-60$ & $13(92.9$ & 00 & $1(7.1)$ \\
& $>60$ & $6(42.9)$ & $4(28.6)$ & $4(28.6)$ \\
\hline \multirow{3}{*}{ Profession } & Student & $46(94.2)$ & $7(11.3)$ & $9(14.5)$ \\
& Professional Driver & $24(50)$ & $11(22.9)$ & $13(27.1)$ \\
& Seller & $28(70)$ & $3(7.5)$ & $9(22.5)$ \\
& Labourer & $13(61.9)$ & $3(14.3)$ & $5(23.8)$ \\
& Housekeeper & $12(66.7)$ & $2(11.1)$ & $4(22.2)$ \\
& Teacher & $6(54.5)$ & $3(27.3)$ & $2(18.2)$ \\
\hline
\end{tabular}

TBI: Traumatic Brain Injury; SI: Spinal Injury.

Table 2. Patient distribution according to age and sex.

\begin{tabular}{ccccc}
\hline \multirow{2}{*}{ Variable } & \multicolumn{4}{c}{ Sex Frequency (\%) } \\
\cline { 2 - 5 } & $\leq 15$ & Male & Female \\
\hline \multirow{2}{*}{ Age } & $16-30$ & 82 & 7 & $103(51.5)$ \\
& $31-45$ & 24 & 21 & $32(16)$ \\
& $46-60$ & 10 & 8 & $14(7)$ \\
& $\geq 60$ & 8 & 4 & $14(7)$ \\
& Total (\%) & $154(77)$ & $46(23)$ & $200(100)$ \\
\hline
\end{tabular}


victims were in driving positions (Table 3). All patients were transported by non-medical personal motor vehicle to the hospital. In traumatic brain injured (TBI) patients, the most common symptom on admission was headache $(81.0 \%)$ followed by dizziness $(74.0 \%)$ of cases (Table 4). A focal neurologic lesion was present in 32 patients (23.17\%). According to the severity classification, patients in group 1 (low risk) represented $62.08 \%$. They did not require any radiologic investigation, whereas those in groups 2 and 3 where the risk was moderate and high, respectively $20.09 \%$ and $16.03 \%$, systematically performed a cervical and cranial X-ray. No patient was referred to a Neurosurgery department, and all living patients were discharged home during the study period with minimal disability.

Patients classified with group 2 and 3 severity score received medical treatment consisting of fluid resuscitation with crystalloids, blood transfusion, acetaminophen, Mannitol, and nasal oxygen with concentrators. $30.7 \%$ of patients received surgical treatment for associated abdominal, orthopedic, and minor procedures for scalp dilacerations. The clinical data and the severity group are summarized in Table 5. Twenty-eight death was recorded in the first $24 \mathrm{~h}$ of admission (16.3\% mortality), all of them had a severity score of $3($ GSC $<9)$.

Table 3. Patient distribution according to victim type.

\begin{tabular}{ccc}
\hline Victime type & Number $(\mathbf{n})$ & Frequency (\%) \\
\hline Driver & 63 & 45.7 \\
Passenger & 56 & 40.6 \\
Bystander & 19 & 13.8 \\
TOTAL & 138 & 100.0 \\
\hline
\end{tabular}

Table 4. Patients distribution according to admission symptoms.

\begin{tabular}{ccc}
\hline Motifs & Numbers (n) & Frequency (\%) \\
\hline Headache & 162 & 81.0 \\
Dizziness & 149 & 74.0 \\
Brief loss of consciousness & 64 & 32.0 \\
Back pain & 64 & 32.0 \\
Neurologic deficit & 54 & 27.0 \\
Memory loss & 22 & 11.0 \\
Epistaxis & 22 & 11.0 \\
Agitation & 19 & 9.5 \\
Vomiting & 4 & 2.0 \\
\hline
\end{tabular}

Table 5. Patients distribution according to the severity classification.

\begin{tabular}{ccc}
\hline Severity Group & Number $(\mathbf{n})$ & Frequency (\%) \\
\hline Group 1 & 108 & 62.8 \\
Group 2 & 36 & 20.9 \\
Group 3 & 28 & 16.3 \\
Total & 172 & 100.0 \\
\hline
\end{tabular}




\section{Discussion}

The hospital frequency of $17.76 \%$ is much lower than that found by Beavogui $\mathrm{K}$. et al. in 2006 at the CHU Donka, 84.51\% [7]. This lower incidence could be explained by the different practice settings and the referral bias. The regional hospital of Kindia is a general hospital, and the Donka study was conducted in a hospital with a neurosurgery department dedicated to the care of neurotrauma. The actual frequency is hidden because only a certain proportion of all traumatic brain injuries will reach the hospital. Many of those with severe injuries may have died in the prehospital setting, and many with mild injuries may not have sought clinical care.

The localization of the trauma in our cohort is comparable to the results published in 2012 in Guinea by Béavogui et al., in which the location of the trauma was on the brain in $82.0 \%$ of cases, and the spinal cord in $8.9 \%$ of patients and mixed in $9.1 \%$ [2].

The predominance is very active males (20 - 30 years) is consistent data both in local and international studies [2] [8] [9]. The most agreed explanation is that active young males are more exposed to work-related hazards as the primary source of income and more vulnerable in the outside environment.

The more significant contributor to neurotrauma in our study was MVA, with motorcyclists being the major contributor to the cohort. This finding is consistent with most local and other low-income countries' studies and is highly indicative of the deficiencies in road safety enforcement and awareness of the Guinean motorcyclists [8] [10] [11]. The same has been found In the Western world [12], where MVA is reported as the main etiology of neuro-trauma (65\%) cases, followed by assaults in $17 \%$ of cases.

Motorcycle-to-motorcycle collision was responsible for more than a third of neurotraumas. In our study, data corroborated by that of Madougou et al. [13] in Benin in 2016 reported that motorcycle-motorcycle type accidents were the most frequent, i.e., 32\%, followed by motorcycle-auto type accidents. This result is comparable to that of Sylla N. et al. in Boke, who also reported that drivers were the most numerous victims, i.e., $47.8 \%$ [14]. On the other hand, it is different from that of Lacheheb M [15], in 2013 in Morocco who reported that pedestrians represented $54.01 \%$ of victims. Better efficiency can explain this slight difference between Guinea and Morocco in implementing road safety measures in middle-income countries than in low-income countries.

It is essential to understand the dynamics of vehicular injuries in rural Guinea. Most vehicles owned in rural areas are motorcycles. The lack of safety laws application like helmet or seatbelt use and poor road infrastructure (road lighting, traffic signals, or guard railing) is consistent with the results from multiple studies in rural hospitals in low- and middle-income countries [16] [17] [18].

This set of practices' originality is that the hospital has no computed Tomography apparel for an appropriate assessment of severe neural injuries and no Intensive care unit to treat those critical patients. There is no medicalization of 
patient transfers and insufficient networking between peripheral health centers and tertiary hospitals. These flaws resulted in the high mortality found in the moderate and severe neurotrauma groups. In comparison, Bah et al. found lower mortality [6] in their study of the outcome of severe traumatic brain injuries in the neurosurgery department of the leading tertiary referral hospital of the capital of the same country, with an Intensive Care Unit department, a CT and an On-call neurosurgeon available all day.

No patient was referred to neurosurgery during the study period, highlighting the lack of efficient inter-hospital networking, appropriate triage skills from general surgeons in those hospitals, and a precise national routing for the brain-injured patient.

Overall, data from this cohort shows a benign profile in the analyzed patients: $32 \%$ didn't report any loss of consciousness, $62.08 \%$ were graded as group 1 according to the severity, the lethality was low, and the majority of the patient received only medical treatment and discharged home. It is consistent with Sylla et al. in their study [14], but the contrast with the results from Beavogui et al. in 2012 [2] and Bah et al. in 2020 [6] because those studies were carried in University hospitals with neurosurgical department and intensive care unit that attracts complex neurotrauma care from all the country. Of note, there is no prehospital management in the whole country; we can assume most of these patients never make it to the hospital for proper management, and even if they do, the lack of triage competence and CT scan in regional hospitals prevent us from getting an accurate picture on the true incidence and severity of neurotraumas in rural areas [16] [19] [20].

It was the main limitation of our study, along with the lack of long-term follow-up, an imprecise collection, and analysis of the details preceding the MVA.

Nonetheless, this study gives an approximate assessment of the magnitude of the burden of neurotrauma, the needs to define reachable goals in prehospital care in low resources countries like Guinea, an improvement in the availability of imaging and neurosurgery equipment, and a nationwide on-call system of Neurosurgery with electronic transfers of images and expert opinion between tertiary and rural hospitals.

\section{Conclusion}

The demographic of this cohort fits well with most published studies in the world, both from high and low-income countries. The clinical data and outcomes are much more typical of rural community hospitals where mild cases do not seek medical attention, and severe cases die before getting to the hospital. A computerized trauma registry and the development of prehospital care are essentials to define a clear picture of the epidemiology of neurotraumas in rural Guinea and guide the health authorities to address the problem.

\section{Conflicts of Interest}

The authors declare no conflicts of interest regarding the publication of this paper. 


\section{References}

[1] Coronado, V.G., Thurman, D.J., Greenspan, A.I. and Weissman, B.M. (2009) Epidemiology. In: Jallo, E. and Loftus, C.M., Eds., Neurotrauma and Critical Care of the Brain, Thieme, New York, Stuttgart.

[2] Beavogui, K., Koïvogui, A., Souare, I.S., Camara, D., Cherif, M., Dramou, B., et al. (2012) Profil des traumatismes crânio-encéphalique et vertébro-médullaire liés aux accidents de la voie publique en Guinée. Neurochirurgie, 58, 287-292. https://doi.org/10.1016/j.neuchi.2012.05.006

[3] Odimba, E.B. (2007) Aspects particuliers des traumatismes dans les pays peu nantis d'Afrique. Académie Nationale de Chirurgie, 6, 44-46.

[4] Matin, M. and Didier, J. (2012) Fréquence et facteurs de risque de l'hypertention intracrânienne à la phase précoce du traumatisme crânien grave. Annales Françaises d Anesthésie et de Réanimation, 23, 930-945.

[5] Lonjon, N., Perrin, F.E., Lonjon, M., Fattal, C., Segnarbieux, F., Privat, A., et al. (2012) Les lésions médullaires traumatiques: Epidémiologie et perspectives. Neurochirurgie, 58, 293-299. https://doi.org/10.1016/j.neuchi.2012.06.003

[6] Bah, A.B., Donamou, J., Diawara, S., et al. (2020) Prise en charge des traumatismes craniens graves à l'hôpital national Donka de Conakry: Analyse de 48 cas 2020 . Journal de Neurologie Neurochirurgie Psychiatre, 1, 28-32.

[7] Beavogui, K., Souare, I.S., Thipoua, A.J., Diawara, S., Bangoura, S.A. and Cissé, A. (2006) Morbidité et mortalité hospitalière dans le service de neurochirurgie de l'hôpital national Donka-Guinée. Neurochirurgie, 52, 494-495. https://doi.org/10.1016/S0028-3770(06)71316-9

[8] Samaké, B.M., Coulibaly, Y., Diallo, A., Tchamko, F.R.D. and Touré A. (2010) Traumatisme cranio encéphalique à l'hôpital Gabriel Toure. Mali Médical, No. 4, 1-2.

[9] Bemora, J.S., Rakotondraibe, W.F., Ramarokoto, M., Ratovondrainy, W. and Andriamamonjy, C. (2017) Aspects épidémiologiques des traumatismes du rachis: A propos de 139 cas. Pan African Medical Journal, 26, Article No. 16. https://doi.org/10.11604/pamj.2017.26.16.11350

[10] Kpelao, E., Diop, A., Beketi, K., Tine, I., Thioub, M., Thiam, A.B., et al. (2013) Problématique de la prise en charge des traumatismes graves du rachis cervical en pays sous-développé. Neurochirurgie, 59, 111-114. https://doi.org/10.1016/j.neuchi.2013.04.008

[11] Motah, M., Sende, C.N., Beyiha, G., Belley, P.E., Malongte, N.C., Gonsu, F.J., et al. (2011) Prise en charge des traumatismes crâniens isoles a l'hôpital général de douala. Health Science and Diseases, 12, 1-6.

[12] Matin, M., Didier, J., et al. (2012) Fréquence et facteurs de risque de l'hypertention intracrânienne à la phase précoce du traumatisme crânien grave. Annales Françaises d Anesthésie et de Réanimation, 23, 930-945.

[13] Madougou, S., Chigblo, P.S., Tchomtchoua, A.S., Lawson, E., Yetognon, L. and Hans-Moevi Akue, A. (2016) Incidence et impacts des accidents de la voie publique chez les conducteurs de taxi-moto en milieu tropical. Revue de Chirurgie Orthopédique et Traumatologique, 102, 211-214. https://doi.org/10.1016/j.rcot.2016.01.005

[14] Sylla, N., Beavogui, K., Souare, I.S., et al. (2011) Profil des traumatismes vertebromedullaires (TVM) dans la region administrative de Boke. $2^{\mathrm{e}}$ Congres de la Societe Senegalaise de Neurochirurgie, 12-13 Mars 2011. 
[15] Lacheheb, M. (2013) Etude du profil épidémiologique des Traumatisés de la voie publique dans les structures d'accueil des urgences du CHR de kénitra durant la période Mars-Avril 2013. Mémoire de fin d'études en épidémiologie de santé publique Maroc. 18.

[16] Bajracharya, A., Agrawal, A. and Yam, B. (2010) Spectrum of Surgical Trauma and Associated Head Injuries at a University Hospital in Eastern Nepal. Journal of Neurosciences in Rural Practice, 1, 2-8. https://doi.org/10.4103/0976-3147.63092

[17] Bhole, A.M., Potode, R., Agrawal, A. and Joharapurkar, S.R. (2007) Demographic Profile, Clinical Presentation, Management Options in Cranio-Cerebral Trauma: An Experience of a Rural Hospital in Central India. Pakistan Journal of Medical Sciences, 23, 724-727.

[18] Garg, N. and Hyder, A.A. (2006) Exploring the Relationship between Development and Road Traffic Injuries: A Case Study from India. European Journal of Public Health, 16, 487-491. https://doi.org/10.1093/eurpub/ckl031

[19] Tazarourte, K., Minh, H.T., Gauthier, A., Gamoura, K. and Bertozzi, N. (2012) Prise en charge initiale des traumatismes crâniens graves et monitorage avant l'arrivée en centre spécialisé. Journal Européen des Urgences et de Réanimation, 24, 201-206. https://doi.org/10.1016/j.jeurea.2012.07.010

[20] Bhatoe, H.S. (2009) Brain Injury and Prehospital Care: Reachable Goals in India. Indian Journal of Neurotrauma, 6, 5-10. https://doi.org/10.1016/S0973-0508(09)80020-8 